\title{
A CONSTRUÇÃO DA \\ ASMA E DA DPOC
}

\section{Hisbello S. Campos}

Médico aposentado do Instituto Fernandes Figueira, Fiocruz, MS.

Mestre e Doutor em Pneumologia pela UFRJ.

\section{Resumo}

Por muito tempo, acreditou-se que as doenças não infecciosas eram resultado da associação de alteraçôes genéticas com a ação de fatores externos. Isso valia para o diabético e a dieta rica em açúcar, para o hipertenso e a comida salgada, para o asmático e os alérgenos, para o portador de DPOC e o cigarro. Com o aprimoramento da tecnologia médica, os detalhes dos mecanismos determinantes de doenças passaram a ser observados e novos personagens vêm sendo incluídos na patogênese de muitas doenças. Hoje, sabemos que a genética e, particularmente, a epigenética, são agentes fundamentais, mas não únicos. $\mathrm{O}$ microbioma e seus desequilíbrios, hábitos do cotidiano, fatores ambientais, emoçóes, dentre outros, são agentes táo importantes quanto os genéticos. O progresso tecnológico aliado à bioinformática vem permitindo desvendar processos moleculares que vêm trazendo informaçôes novas sobre a instalação e a progressáo da asma e da DPOC. Comprovadamente, as duas começam ainda na fase fetal, induzidas por uma mescla de fatores genéticos, epigenéticos, microbiômicos, ligados a hábitos de vida e a fatores ambientais. Os processos de instalação/progressão de ambas compartilham fatores comuns. Com o progresso científico, podemos imaginar um futuro em que possamos prevenir a instalação ou a progressão de ambas, assim como de tantas outras doenças.

\section{Abstract}

For a long time, it was believed that non-infectious diseases were the result of the association of genetic alterations with the action of external factors. This was true for the diabetic and the high sugar 
diet, for the hypertensive and salty food, for the asthmatic and allergens, for the COPD patient and smoking. With the improvement of medical technology, the details of the mechanisms that determine diseases came to be observed and new characters are being included in the pathogenesis of many diseases. Today, we know that genetics, and particularly epigenetics, are fundamental agents, but not the only ones. The microbiome and its imbalances, daily habits, environmental factors, emotions, among others, are as important agents as the genetic ones. Technological progress combined with bioinformatics has been making it possible to unravel molecular processes that have brought new information about the onset and progression of asthma and COPD. It has been proven that both begin in the fetal stage, induced by a mixture of genetic, epigenetic and microbiomic factors, linked to lifestyle and environmental factors. The installation/progression processes of both share common factors. With scientific progress, we can imagine a future in which we can prevent the onset or progression of both, as well as so many other diseases.

Palavras-chave: Asma; DPOC; genética; miRNA; microbioma; fatores ambientais.

Key-words: Asthma; COPD; genetics; miRNA; microbiome; environmental factors.

\section{INTRODUÇÃO}

O desenvolvimento contínuo de novas tecnologias na área da saúde vem permitindo desvendar mecanismos patogênicos desconhecidos até há poucas décadas em inúmeras doenças que sempre comprometeram o cotidiano de milhóes de pessoas. Através de instrumentos e métodos das ciências ômicas, elementos como processos epigenéticos, microbioma, microvesículas extracelulares, microRNA, irritantes respiratórios e alérgenos, assim como fatores do cotidiano (condiçôes geográficas, climáticas e de habitação, hábitos alimentares, uso de fármacos, atividade física, estresse psicológico dentre outros) vêm sendo incorporados à patogênese de muitas enfermidades e vêm mudando a perspectiva com que costumamos ver e tratar essas doenças.

A asma e a doença pulmonar obstrutiva crônica (DPOC) são dois exemplos marcantes dessa mudança. Hoje, sabemos que muitos fatores estão envolvidos na geração, desenvolvimento e desfecho de ambas. De modo complexo, com mecanismos integrados e concatenados, predisposição genética, interação gen-ambiente, fatores pré-natais, microbioma, miRNAs, aspectos dietéticos, estresse psicológico, tipo de parto, fármacos, infecçôes e exposiçôes a endotoxinas e a alérgenos, amamentação, tamanho e estrutura familiar, tabagismo, exposiçóes ocupa- 
cionais e outros fatores estão envolvidos na gênese, desenvolvimento e desfechos da asma e da DPOC ${ }^{1}$. Os fatores causais envolvidos pertencem a diferentes categorias e podem variar sua importância ao longo do tempo, formando uma rede complexa com interações múltiplas em diferentes níveis. Para investigar e desvendar essa rede são necessários recursos tecnológicos avançados, envolvendo plataformas multiômicas que permitam desvendar a integração entre mecanismos epigenômicos, transcriptômicos e microbiômicos envolvidos na determinação da asma e da DPOC.

As duas são o resultado de um processo construtivo no qual fatores genéticos, disbioses no microbioma, instrumentos de comunicação intercelular, estresse emocional e elementos externos são os tijolos. Nesse texto, será comentada a participação desses fatores na gênese da asma e da DPOC.

\section{Asma E DPOC}

A asma e a DPOC são duas das doenças pulmonares crônicas mais frequentes em todo o mundo. Por vezes, a semelhança dos sintomas pode dificultar a diferenciação entre ambas. Possivelmente, as similaridades entre elas decorrem de mecanismos patogênicos parecidos, ou mesmo comuns. As definiçôes usadas para ambas vêm sendo modificadas ao longo do tempo. Até o final da década de 50, havia confusão no uso dos termos asma, bronquite crônica e enfisema. $\mathrm{O}$ marco temporal para definiçóes universalmente aceitas para essas condiçóes foi o Simpósio Ciba, em 1958. ${ }^{2}$ A partir de então, enfisema passou a ser definido com base na anatomia patológica e bronquite crônica com base na cronicidade da tosse produtiva. A introduçáo do conceito de "obstrução reversível ao fluxo aéreo" foi usado na definiçấo da asma. Dez anos depois, Hogg e colaboradores identificam as vias aéreas periféricas como a principal localização da obstrução ao fluxo aéreo na $\mathrm{DPOC}^{3}$ e 36 anos mais tarde descrevem a anatomopatologia da obstrução das pequenas vias aéreas na $\mathrm{DPOC}^{4}$. A definição atual proposta pelo Global Obstructive Lung Disease (GOLD), da Organização Mundial da Saúde (OMS), diz que "Doença pulmonar obstrutiva crônica é uma doença comum, prevenivel e tratável, caracterizada por sintomas respiratórios persistentes e limitação ao fluxo aéreo devida a anormalidades das vias aéreas elou dos alvéolos usualmente causadas por exposiçâo significante a partículas tóxicas ou gases e influenciada por fatores do hospedeiro, incluindo desenvolvimento pulmonar anormal. Comorbidades significativas têm impacto na morbidade e mortalidade."

A DPOC é caracterizada pela obstrução progressiva do fluxo aéreo associada à destruição do parênquima pulmonar, fibrose/destruição das pequenas vias aéreas e/ou hipersecreção de muco. O tabagismo 
é o mais poderoso fator de risco para o desenvolvimento da doença. Investigaçóes desde a fase uterina até a idade avançada revelam efeitos epigenéticos extensos no genoma humano. Esse efeito persiste anos após a parada do fumo. ${ }^{6}$ Além do tabagismo, a inalação prolongada de partículas e gases tóxicos, como os decorrentes da combustáo de produtos da biomassa, também são fatores de risco. ${ }^{7}$

Conceitualmente, asma é uma alteração respiratória que compromete exclusivamente o trato respiratório. Historicamente, asma vem da palavra grega que significa ofegante. Jean Baptiste Van Helmont (1579-1644), médico belga, afirmou que a asma era originária nos foles pulmonares. ${ }^{8}$ Pouco depois, Bernardino Ramazzini (1633-1712) foi o primeiro a descrever a asma induzida pelo exercício. ${ }^{9}$ No final do século XIX, Henry Hyde Salter (1823-71), acreditando que a asma tinha mecanismos neurais e vasculares nos brônquios, propôs uma classificação que incluía asma extrínseca e intrínseca. ${ }^{10}$ Pouco depois, William Osler (1849-1919), definiu asma de modo semelhante ao de Salter, incluindo o conceito de que a estimulação psicogênica poderia causar exacerbaçôes. ${ }^{11} \mathrm{Em}$ 1873, Charles Blackley demonstrou que o pólen era a causa da febre do feno e da "asma pelo feno", sugerindo o caráter alérgico do problema. ${ }^{12}$ Um pouco mais tarde, em 1916, Francis Rackemann, de forma semelhante à Henry Salter, também propôs caracterizar a asma como intrínseca (não-alérgica) ou extrínseca (alérgica). ${ }^{13}$

A partir daí, a sensibilização antigênica foi sendo incorporado às causas da asma. ${ }^{14} \mathrm{~A}$ alergia é um fator frequentemente associado à asma. Tradicionalmente, as doenças alérgicas eram vistas como resultado de respostas imunes mediadas pela imunoglobulina $\mathrm{E}$ (IgE). Atualmente, novos fatores são incluídos na predisposiçấo, iniciação ou na exacerbação da alteração imune observada nas doenças alérgicas, tais como disfunção na barreira epitelial, perda da tolerância imune, alteraçóes no microbioma intestinal, particularidades nos microbiomas específicos de cada órgão envolvido na manifestação alérgica, dieta e idade. Aparentemente, a lesão das superfícies epiteliais é a etapa inicial na origem das manifestaçôes das doenças alérgicas. Os epitélios pulmonar, intestinal e da pele têm propriedade sensorial aos estímulos ambientais e são afetados pelas alteraçóes do microbioma, modificaçóes epigenéticas, poluentes aéreos, alérgenos alimentares, mudanças da dieta, fármacos e produtos químicos nos materiais de limpeza modernos. Em conjunto, esses fatores levam a alteraçóes dos epitélios citados, direcionando uma resposta imune do tipo 2, subjacente às doenças atópicas. $\mathrm{Na}$ interface alergia/asma, encontramos 1) mutaçóes que resultam na perda de função das filagrinas comprometendo a integridade da barreira epitelial; 2) mecanismos de reparo e crescimento alterados; 3) interação entre 
características geneticamente determinadas no epitélio brônquico e os efeitos decorrentes da exposição a vírus, alérgenos ou agentes microbianos; alteraçóes do microbioma e poluentes aéreos. Todos são fatores importantes na gênese e exacerbações da asma. ${ }^{15}$

No final do século XIX, o conceito de que a asma era uma doença inflamatória foi apontado por Fowler e Godlee, que em 1898, descreveram o "edema inflamatório ou catarro agudo nas membranas mucosas brônquicas" ", e por Osler, que, em 1901, afirmou que "em muitos casos, (a asma) é uma forma especial de inflamação dos brônquios menores". ${ }^{11}$ Com o passar do tempo, o conhecimento sobre os processos inflamatórios envolvidos foi aumentando e novos conceitos foram sendo adicionados na definição de asma. Atualmente, o Global Initiative for Asthma (GINA), da OMS, define asma como "uma doença heterogênea, usualmente caracterizada por inflamaçâo crônica da via aérea. É definida pela história de sintomas respiratórios tais como sibilos, falta de ar, opressão torácica e tosse que variam ao longo do tempo e em intensidade, junto com limitação variável do fluxo aéreo expiratório. A limitação ao fluxo aéreo pode se tornar persistente posteriormente. " $\mathrm{Ou}$ seja, a definição atual opta por indicar que há formas de asma que incluem a inflamação crônica em sua patogenia e outras que não incluem, que o diagnóstico é clínico e que o grau da obstrução ao fluxo aéreo varia e pode vir a ser fixo. Coincidentemente, os dois últimos itens — diagnóstico clínico e obstrução fixa - também são usados na definição da DPOC.

Ambas, asma e DPOC, sempre foram vistas como entidades separadas, embora haja semelhança entre diversos aspectos das apresentaçóes clínicas e funcionais. $\mathrm{Na}$ década passada surgiu um novo conceito que, mesmo mantendo a separação entre as duas, passou a usar a possibilidade de superposição de ambas na mesma pessoa como uma explicação para aquelas apresentaçóes nas quais a diferenciação clínica entre ambas é praticamente impossível — "Overlap syndrome". ${ }^{18}$

A compreensão do papel das citocinas pró e anti-inflamatórias na asma e na DPCO foi um passo importante na busca para desvendar os mecanismos patogênicos envolvidos. Citocinas derivadas de células Th1, Th2, Th9, Th17 e de células B, epiteliais, dendríticas, mastócitos, eosinófilos, neutrófilos, basófilos, cujas produçôes são controladas por mecanismos genéticos e epigenéticos, com a participação do microbioma, induzem o desenvolvimento da asma, contribuem para as alteraçóes anatomopatológicas e modulam formas alérgicas e não alérgicas. A atração/ ativação de células inflamatórias para as vias aéreas promovida pelas citocinas resulta não apenas em inflamação/lesão tecidual como num processo de reparo alterado, com secreção de outras citocinas e fatores de crescimento que induzem mudanças estruturais fixas, remodelamento brônquico. ${ }^{19}$ De acordo com 
suas funçôes, as citocinas podem ser divididas em grupos. No primeiro, estariam aquelas responsáveis pelos efeitos da interaçáo entre o epitélio brônquico e o ambiente. No segundo, as citocinas que direcionam a polarização linfocitária (Th1 e Th2) nos processos imunes e inflamatórios envolvidos. No terceiro grupo, as citocinas responsáveis pela lesão tecidual. Além das citocinas, quimocinas têm papel relevante no processo lesivo, atraindo células inflamatórias da circulação para o pulmão. Inflamasomas, complexos multiproteicos que regulam a expressão de citocinas pró-inflamatórias em resposta a sinais externos e endógenos de perigo são outros personagens importantes. Do mesmo modo, o estresse oxidativo e proteases participam da gênese das alteraçóes observadas na asma e na DPOC..$^{20}$ Nesse grande grupo de agentes diretos, indiretos e mediadores envolvidos na patogenia de ambas, as secretoglobinas (SCGBs) vêm assumindo papel de destaque. Os SCGBs constituem uma família de onze membros (onze genes e cinco pseudogenes foram identificados) que são mediadores anti-inflamatórios e imunomoduladores produzidos pelas superfícies epiteliais e tecidos glandulares. Estão envolvidas na asma alérgica, DPOC e fibrose cística. $\mathrm{Na}$ asma, o SCGB1A1 encontrado em concentraçóes séricas, urinárias ou no lavado brônquico menores que em pessoas saudáveis. $\mathrm{O}$ papel de outros membros da família ainda não está claro, mas o SCGB3A2 é encontrado em concentraçóes mais elevadas na asma e na rinite. Na DPOC, o nível de SCGB1A1 também é mais baixo do que em normais e está inversamente correlacionado com a gravidade da doença. ${ }^{21} \mathrm{O}$ efeito de uma alteração genética ou epigenética reduzindo a expressáo dos genes das secretoglobinas seria uma possível interpretação para esses achados.

Com a evolução do conhecimento, novas técnicas sofisticadas de identificação/análise das alteraçôes presentes nas enfermidades passaram a ser empregadas. O emprego de novas tecnologias genéticas e de instrumentos que permitem análises moleculares do funcionamento celular, a asma e a DPOC passaram a ser vistas como exemplos de doenças resultantes da interaçáo de diversos elementos: fatores genéticos e epigenéticos, mecanismos de reparo e de envelhecimento celulares alterados, disbioses no microbioma, estimulação ambiental, estresse emocional nos períodos pré-natal e pós-parto, entre outros. Tanto na asma como na DPOC há uma grande diversidade de mecanismos moleculares e imunológicos (endotipos) influenciados por um número elevado de fatores (genéticos/epigenéticos, microbiômicos, emocionais, dietéticos, dependentes de estilo de vida, estímulos ambientais) que resultam na inserção dessas doenças na vida de uma pessoa. Ambas são vistas sob a forma de um amplo espectro de apresentaçóes clínicas, disfunções respiratórias, respostas ao tratamento e desfechos. Nessa rede complexa, endotipos 
(mecanismos patogenéticos definidos) resultantes dessa mescla de fatores podem se alternar ou coexistir, e incluir outros processos, gerando diversidade e dinamismo nas apresentações clínicas.

Abaixo, serão apresentados os principais personagens envolvidos na inserção/ progressão da asma e da DPOC no organismo humano. Em seguida, será comentado como esses elementos estão integrados de modo concatenado numa rede complexa e de múltiplos níveis.

\section{Redes GeNÉTICAS, EPIGENÉTICA E MICRORNAs}

$\mathrm{O}$ envolvimento genético na asma e na DPOC é indiscutível. Aparentemente, genes localizados em diferentes regióes nos cromossomos participam de modo "independente" das diferentes formas de ambas. As apresentaçóes clínicas (fenótipos) e seus mecanismos determinantes (endotipos) são a expressáo e os resultados de uma interação complexa entre redes genéticas e diversos outros fatores. ${ }^{22}$ Certamente, a evolução dos estudos sobre o tema, avaliando os fatores genéticos, epigenéticos, transcriptômicos e proteômicos envolvidos trará luz para essa área e será útil para a futura personalização do tratamento. ${ }^{23}$

$\mathrm{O}$ primeiro gen de susceptibilidade para a asma identificado foi o $A D A M 33$, localizado no cromossomo 20p13. Expresso em muitas células do trato respiratório, o ADAM33 foi associado ao remodelamento e à hiper responsividade brônquica levando à proliferação de fibroblastos ativos, miofibroblastos e músculo liso através da unidade trófica epitélio-mesenquimal. ${ }^{24} \mathrm{O}$ IRAKM é um gene de susceptibilidade da asma de início precoce $^{25}$ e o PCDH1 está associado à asma de início na infância e a de início na idade adulta. ${ }^{26}$ Como exemplo da multiplicidade de fatores envolvidos na asma, estudos de associação ampla de genomas (Genome-wide Association Studies - GWAS) identificaram 128 polimorfismos de nucleotídeo único (SNPs) independentes associados com a asma. A interpretação funcional desses SNPs apontou 161 possíveis alvos terapêuticos dos quais já existem medicamentos para 16 deles. IL7R, CCR7, IL2RB, GPR184 e ITGB8 são exemplos de alguns desses. GWAS são usados para identificar redes biológicas subjacentes a doenças complexas. Os genes alvo não agem isoladamente, mas em redes biologicamente importantes para inserção e desenvolvimento da doença. Os mecanismos envolvidos no funcionamento dessas redes são complexos e a sua análise depende da possibilidade de associar evidência funcional à variaçáo genética identificada. Por exemplo, o mecanismo associado ao receptor IL-33IL-1RL1 leva à eosinofilia. A ausência de evidência funcional evidenciada até agora não permitiu esclarecer os mecanismos as- 
sociados a 71 (44\% dos 161) genes alvo da asma identificados. ${ }^{23} \mathrm{Em} 2007$, o primeiro GWAS publicado relatou que a variação genética no cromossomo 17q12-21 (codificando ORMDL3 e GSDMB) está associada à asma de início na infância, mas não à asma de início na idade adulta nem à atopia. ${ }^{27}$ $O$ fato de fatores genéticos de risco serem importantes para subgrupos de asmáticos ilustra a complexidade genética envolvida. GWAS identificaram muitas regiōes genômicas associadas a fenótipos da DPOC. Entretanto, ainda resta esclarecer quais os genes chave e variantes funcionais nessas regiōes.

As relaçóes variadas entre os determinantes genéticos da asma e da DPOC e os fenótipos relacionados às duas indicam o valor da genética e dos fatores epigenéticos para a heterogeneidade característica em ambas as doenças. ${ }^{28,29} \mathrm{O}$ conceito antigo (1941) de "um gen, uma enzima, uma função" expressando uma conexão linear simples entre o genótipo e seu fenótipo ${ }^{30}$ não é correto. Combinaçôes de genótipos idênticos e ambientes quase idênticos nem sempre geram fenótipos idênticos. ${ }^{31}$ Exposiçôes na fase fetal ou na vida pós-natal podem gerar distúrbios no "interatoma" (rede de interações proteína-proteína representando todas as interaçóes moleculares que ocorrem dentro de uma célula em particular), levando ao maior risco de desenvolver doenças complexas. ${ }^{32}$ Diferentemente do genoma, o interatoma é dinâmico. Muitas interações são transientes e outras ocorrem apenas em determinados contextos celulares ou em momentos particulares do desenvolvimento. Considerando as propriedades dos sistemas celulares e a diversidade/complexidade das redes envolvidas, é possível que fenótipos resultem de perturbaçóes entre esses atores, mais do que de genótipos apenas.

A epigenética descreve mecanismos herdáveis de regulação da expressão do gen que ocorrem sem alteração direta da sequência do DNA. ${ }^{34}$ Há diferentes tipos de controle epigenético, que podem ser divididos em mecanismos clássicos e não clássicos. Os clássicos incluem metilação do DNA, modificaçóes pós-translacionais da histona (acetilação, metilação, fosforilação e outros). Os não clássicos são mediados por elementos de controle pós-transcricional, como os microRNAs (miRNA). Esses últimos são pequenas cadeias simples de RNA não codificante, com -22nucleotídeos, que se liga em sequências complementares nos RNAm alvos, usualmente resultando em silenciamento do gen. ${ }^{35,36}$ miRNAs são considerados reguladores chave de todas as funçôes celulares $^{37}$, controlando a expressão de 30 a $60 \%$ dos genes humanos. ${ }^{38}$ São cruciais nos processos biológicos, incluindo proliferação e diferenciaçáo celular, apoptose e nas respostas imunes. $\mathrm{O}$ equilíbrio entre regulação positiva e negativa dos miRNA tem papel relevante na patogênese da asma. ${ }^{39}$

Os mecanismos epigenéticos são a 
ponte entre a base genética e os fatores de risco ambientais que contribuem para a patogênese de doenças pulmonares ${ }^{40}$, como a asma $^{41}$ e a DPOC $^{42}$. Como um exemplo, a metilação do DNA tem papel importante nas fases iniciais do desenvolvimento fetal e pode ser impactada por exposiçóes ambientais, influenciando a susceptibilidade individual para asma e DPOC posteriormente. ${ }^{43}$ O valor dos fatores étnicos ainda está envolto em incertezas e será comentado adiante. ${ }^{44}$

\section{Vesículas Extracelulares}

As membranas biológicas (MBs) estão intimamente envolvidas em quase todos os processos biológicos, estabelecendo e mantendo gradientes transmembranas, compartimentalizando reaçôes bioquímicas dentro de domínios funcionais distintos, controlando 1) o transporte para dentro e para fora da célula; 2) a comunicação intra e intercelular; 3) o processo de reconhecimento célula-célula e 4) os eventos de transdução de energia. MBs têm espessura mínima $(<10 \mathrm{~nm})$ e composiçáo complexa, com centenas de proteínas, milhares de lipídeos e numerosos carbohidratos na superfície, todos em fluxo constante. ${ }^{45}$

A comunicação intercelular é uma função fisiológica crucial em organismos multicelulares para o compartilhamento de sinais e recursos. Essa comunicação é um processo dinâmico que envolve a propagação de sinais via contato direto célula-célula ou por vesículas extracelulares (VEs) para células próximas ou distantes. A partir das $\mathrm{MBs}$, as VEs são liberadas por praticamente todos os tipos celulares e reconhecidos como mediadores importantes da comunicação intercelular. Elas transportam e transferem uma grande variedade de moléculas, como microRNAs (miRNAs), RNA mensageiros (RNAm), ácidos nucleicos, lipídeos e proteínas para outras células, regulando suas funções e contribuindo tanto para as funçôes biológicas como para a patologia de diversas doenças. As VEs incluem exossomos, microvesículas e corpos apoptóticos.

- Exossomos: vesículas da membrana liberadas diretamente do interior da célula para o meio extracelular; atuam promovendo e regulando a resposta imune.

- Microvesículas: vesículas da membrana situadas na superfície celular; determinantes de vários processos biológicos, incluindo a comunicação celular.

- Corpos apoptóticos: resultantes da fragmentação dos constituintes celulares e envolto por membrana. ${ }^{46}$

Revelando um desenho perfeito para as funçóes que desempenham, as VEs exploram mecanismos para evitar sua degradação ao serem endocitadas pelas células alvo com consequente liberação de seu conteúdo (proteínas citosólicas, lipídeos e miRNA, 
por exemplo) via fusão de membranas. ${ }^{46}$ A partir daí, o miRNA transferido passa a modular o comportamento dessas células podendo gerar as disfunçóes observadas em tantas doenças, asma e DPOC incluídas.

\section{FATORES AMBIENTAIS}

Não é novidade que características do hospedeiro predispóem para a asma ou para a DPOC. Entretanto, a expressão "características do hospedeiro" envolve mais do que atributos individuais, genéticos. A asma e a DPOC são produtos de um enredo complexo e variável, no qual atuam personagens de todos os tipos. Fatores étnicos, socioeconômicos, demográficos, estilo e hábitos de vida se unem aos genéticos, microbiômicos, imunes e emocionais, moldando ambas as doenças e gerando heterogeneidade nas apresentaçóes clínicas e no tipo/intensidade da inflamação da via aérea. Nesse cenário, falar de fatores ambientais, inclui comentar sobre agentes relevantes na patogênese das duas, tais como exposição a micróbios e alérgenos, poluição ambiental, tabagismo, dietas, hábitos de vida, higiene exagerada e outros também influenciam o desenvolvimento de ambas. A partir dos resultados dos GWAS, compreendeu-se que nem mesmo um único SNP permitia explicar completamente a heritabilidade $\mathrm{da}$ asma e da DPOC. Dessa forma, mecanismos epigenéticos envolvidos na interação do gene com o meio ambiente passaram a ser vistos como importantes na gênese de ambas as doenças. ${ }^{47,48}$

O impacto da asma sobre a população mundial é grande. Estima-se que 300 milhóes de pessoas sejam asmáticas. ${ }^{49}$ A variação geográfica de sua prevalência na população infantil é grande, indo de 2 a 32\% nos diferentes países. ${ }^{50}$ A DPOC afeta cerca de 300 milhóes de pessoas em todo o mundo, causando a perda de 64 milhóes de anos de vida por incapacidade. Estima-se que 25 a $45 \%$ dos doentes nunca tenham fumado; em 14\% das vezes, a doença é atribuída ao risco ocupacional. As análises epidemiológicas da asma e da DPOC evidenciam o papel de fatores externos, ambientais e étnicos. O risco para DPOC é maior em populações rurais, quando comparadas às urbanas. Afro-americanos que nunca fumaram têm prevalência desproporcionalmente maior e hispânicos têm menor prevalência, indicando que fatores étnicos estão envolvidos. ${ }^{51}$ Estudo transversal britânico procurando avaliar se fatores étnicos modulavam o risco de DPOC analisou dados primários de 358.614 (47,6\% brancos, 20\% negros e $5 \%$ asiáticos) pacientes atendidos em Londres. A prevalência global de DPOC $1,01 \% ; 1,55 \%$ em brancos, 0,58\% em negros e $0,78 \%$ em asiáticos. ${ }^{52}$ Estudo norte-americano também observou que, nos Estados Unidos da América (EUA), há 
discrepâncias raciais e étnicas na prevalência, mortalidade e resposta ao tratamento. Os autores supuseram que as disparidades poderiam ser explicadas por variaçóes específicas, étnicas e raciais, moduladas por fatores de risco genéticos, ambientais, sociais e psicológicos. ${ }^{53}$ Nesse tipo de análise, é importante lembrar que fatores sociodemográficos podem influenciar os resultados.

Avaliar o papel das variantes étnicas na determinação da asma e da DPOC traz desafios devidos à heterogeneidade dos fenótipos de ambas. Dados de países com populaçóes de múltiplas etnias mostram variação ampla na prevalência relativa dessas doenças. Por exemplo nos EUA, as taxas de prevalência da asma variam de 6,6\% em hispânicos, 7,8\% em caucasianos, 10,3\% em afro-americanos e 13,7\% em porto-riquenhos. Entre crianças, a disparidade é maior; $7,4 \%$ em norte-americanos brancos e 13,4\% em afro-americanos. ${ }^{54,55,56,57}$ Vários são os fatores intervenientes na análise do papel dos fatores étnicos na prevalência de doenças. Higiene, fatores metabólicos e nutricionais, poluição aérea relacionada ao tráfego, prevalência de tabagismo, estresse, variações étnicas no microbioma e fatores genéticos podem modular as incidências e prevalências de diferentes doenças, asma e DPOC incluídas. Diferenças nas condições ambientais urbanas e rurais também são determinantes das diferenças nas prevalências das diversas formas clínicas, particularmente na asma.

\section{Microbioma}

O termo microbioma denomina um ecossistema complexo que inclui o conjunto de microrganismos (microbiota - bactérias, vírus, fungos, protistas, algas e archaea) e um determinado habitat (corpo humano). $\mathrm{O}$ número de microrganismos presentes é três vezes maior que o número de células do nosso corpo ${ }^{58,59 * 1}$. Em condiçóes normais, esse conjunto de microrganismos mantém uma relação harmônica de simbiose com nosso organismo e tem participaçáo ativa em funçóes fundamentais para a vida humana. Por exemplo, graças ao microbioma, somos capazes de digerir os alimentos, temos um sistema imune e defesas contra infecçôes e as funçôes cerebrais normais. Comparativamente, o genoma total contido no microbioma é maior que o nosso. Há efeitos epigenéticos bilaterais, com o nosso genoma e o do micobioma, influenciando um ao outro. A diversidade microbiana, tanto na sua composição como na sua função, depende do local anatômico onde a microbiota está. Em condiçóes saudáveis, o conjunto de microrganismos é diversificado, estável, resistente e resiliente, e tem a capacidade de

1 Estima-se que o corpo humano de um homem com 70 quilos contenha 3,72 x 1013 (37 trilhões) de células de cerca de 200 tipos, e que nosso microbioma englobe mais de 100 trilhões de micróbios. 
retornar às condições pré-perturbação ${ }^{60}$ As microbiotas intestinal (MI) e pulmonar (MP) são essenciais para a manutenção da saúde.

Aparentemente, o momento do parto representa a primeira exposição maciça do recém-nato a uma microbiota complexa oriunda da mãe. ${ }^{61}$ A partir da colonização do trato digestivo, outras microbiotas vão atingir outras regiōes do corpo, como fígado, cérebro, aparelho gênito-urinário, pulmão e pele. A composição de cada uma das microbiotas é modulada pelas condiçóes ambientais locais e passa a desempenhar tanto funções equivalentes às de outras microbiotas (redundância funcional) ${ }^{62}$ como funçôes específicas. Por exemplo, a MI tem como funçôes a produção de vitaminas, absorção de íons, proteção contra patógenos, desenvolvimento histológico, fermentar os alimentos, amplificar as funçôes imunes, entre outras. Em cada regiáo do trato digestivo, desde a boca até o ânus, a composição e diversidade da MI é diferente e adaptada às funçôes locais. $\mathrm{O}$ desenvolvimento concomitante da MI e do sistema imune são processos coordenados entre si e o aumento da variedade modula a maturaçáo do sistema imune do hospedeiro. ${ }^{63} \mathrm{O}$ sistema imune incorpora respostas adaptativas específicas para os novos antígenos que vão surgindo enquanto a MI é progressivamente afetada pelas mudanças ambientais, num processo de desenvolvimento caracterizado pela plasticidade. ${ }^{64}$ Existe um processo de "comunicação bidirecional" entre as microbiotas dos diferentes órgãos, chamado "eixo". Dessa forma, o eixo intestino-pulmão inclui a regulaçáo das respostas imunes pulmonares.

\section{Origens da Asma E dA DPOC}

Hoje, sabemos que o risco de ser asmático começa ainda na fase uterina durante o desenvolvimento pulmonar, momento em que o feto está particularmente vulnerável às agressóes oriundas de um sistema imune imaturo, do sistema neuroendócrino em formação e das defesas antioxidantes. A partir daí, o bebê continuará vulnerável aos processos gerados por sistemas ainda em desenvolvimento e, dependendo do arranjo entre os diversos fatores envolvidos, seu sistema respiratório pode passar a ter comportamento exageradamente reativo aos fatores externos. Os efeitos pré-natais da asma materna na regulaçáa dos genes fetais nas células das vias aéreas persistem na idade adulta graças a mecanismos regulatórios dos miRNA. ${ }^{65}$

Apesar do peso do componente genético, GWAS identificaram um número de genes menor que o necessário para justificar a variância fenotípica da asma ${ }^{66,67}$, levantando a possibilidade de outras fontes potenciais para essa variância. Dessa forma, surge a hipótese de que modificaçóes epigenéticas causadas por interaçóes entre o genoma e o 
ambiente sejam responsáveis por parte da hereditariedade e da plasticidade das respostas imunes. ${ }^{68}$ Comprovando a importância da epigenética na gênese da asma, foram identificadas metilaçóes específicas associadas com inflamação alérgica nas vias aéreas e com alterações no funcionamento de células imunes, evidenciando um papel regulatório da metilação na patogênese da asma. ${ }^{69}$ Um passo importante para o controle da asma será dado com a compreensão sobre como mecanismos epigenéticos influenciam a susceptibilidade e a gravidade da asma, e como são deflagrados.

A arquitetura genética da DPOC ainda é grandemente desconhecida e a totalidade dos estudos sobre o tema avaliam adultos com idade superior a 40-50 anos. As investigações deveriam incluir jovens fumantes e não fumantes para tentar diferenciar o impacto de determinantes genéticos dos processos de redução da função pulmonar daqueles responsáveis por declínio acelerado da função pulmonar associado à DPOC. $^{70}$ Um grande GWAS envolvendo 35.735 portadores de DPOC e 222.076 controles identificou 82 regióes cromossômicas associadas à DPOC. Em 14 dessas regióes foi encontrada associação também com asma e fibrose pulmonar, ${ }^{71}$ revelando áreas comuns na genética da asma e da DPOC. Estudos associam genes à susceptibilidade comum para asma e DPOC. Alguns exemplos: 1) uma variação do ADAM33 foi associado à susceptibilidade para DPOC $;^{72}$ 2) foi demonstrado que uma variação no IL13, anteriormente associada à susceptibilidade para asma em GWASs ${ }^{73}$, também tinha efeito interativo com a intensidade do fumo e função pulmonar. Diversos genes relacionados à inflamação brônquica em asmáticos

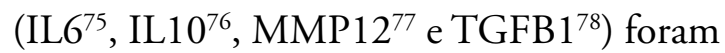
também relacionados à DPOC. Um estudo buscando entender a imbricação de padrōes genéticos entre doenças frequentemente associadas avaliou o perfil de expressão dos genes relacionados ao epitélio da via aérea. $\mathrm{O}$ racional desse estudo partiu do princípio de que o tabagismo causaria injúria molecular nas células epiteliais do trato respiratório e que o perfil de expressão genética refletiria tanto a resposta do hospedeiro como a lesão causada pelo fumo. A heterogeneidade no perfil de expressão foi associada ao câncer de pulmão relacionado ao tabagismo, evidenciando o valor dos mecanismos epigenéticos na definição de doenças. ${ }^{79}$

Classicamente, a gênese da DPOC é associada ao tabagismo. Inegavelmente, fumar ou inalar regularmente partículas ou gases tóxicos são causas importantes da doença, mas não as únicas. A interação genesambiente é a grande força motriz da DPOC, sendo a responsável pela tradução anátomoclínica dos danos decorrentes do tabagismo. Isso é comprovado pelo fato de menos que $50 \%$ dos fumantes desenvolverem DPOC. ${ }^{80}$ Assim como na asma, a inflamação das vias 
aéreas tem papel central nas alteraçóes anatomopatológicas presentes na DPOC. ${ }^{81}$ $\mathrm{O}$ papel da predisposição genética modulando o papel relevante do sistema imune na gênese da DPOC é bem conhecido. ${ }^{80}$ Qualquer pessoa apresentará resposta imune à inalação de gases tóxicos, mas num portador de DPOC a resposta é sustentada por mais tempo, mais extensa e mais lesiva. Graças a imbricação dos processos envolvidos em ambas as doenças, parte dos mecanismos imunes presentes na DPOC também existem na asma. Por exemplo, a inflamação tipo 2 habitualmente observada na asma também já foi descrita em pacientes com DPOC sem história de asma, o que poderia representar um outro endotipo da DPOC $^{82}$ e estar associada à síndrome de overlaping asma-DPOC, mencionada anteriormente. $^{83}$ Resumindo, mecanismos epigenéticos estão relacionados à inserção da asma e da DPOC na vida do indivíduo desde o período fetal. Naquela fase e no período pós-natal imediato, exposiçôes maternas e do recém-nato definirão as trajetórias rumo à instalação, desenvolvimento e desfechos de ambas as doenças, como de tantas outras. ${ }^{84}$

Um fator particularmente importante na gênese da DPOC é a senescência pulmonar. Numa doença como a DPOC, na qual o envelhecimento pulmonar está acelerado, mecanismos antagônicos ao processo fisiológico de regeneração estão associados a um fenótipo secretório associado à senescência (senescence-associated secretory phenotype - SASP). Nesse fenótipo, ocorre a secreção de moléculas bioativas lesivas inseridas nas células pulmonares através de VEs secretadas por células senescentes. Essas VEs podem gerar disfunçóes em células tronco, que têm função pivotal nos processos de manutenção e reparo de tecidos e órgãos. As VEs de células senescentes também podem agir como moléculas de sinalização induzindo senescência prematura em células vizinhas. ${ }^{86}$ Dessa forma, VEs associadas à senescência podem estar envolvidas na patogênese da DPOC. ${ }^{87,88}$

Os exossomos (categoria de VE), estruturas responsáveis pela comunicação intercelular, transferindo miRNAs e outros produtos de células para células, são efetivos, regulando as respostas imunes nas vias aéreas. Estudos recentes demonstram aumento do número de VEs relacionadas com respostas inflamatórias e ativação endotelial em pacientes com DPOC $^{89}$ e correlação negativa entre os números de VEs no escarro e a função pulmonar. ${ }^{90} \mathrm{O}$ papel fundamental dos miRNAs na patogênese da asma ${ }^{91,92} \mathrm{e}$ da DPOC modulando o comportamento das células envolvidas é indiscutível. Mudanças na expressão de diversos miRNA estão associadas na inserção e progressão da asma e da DPOC. ${ }^{93}$ Cada miRNA pode ter vários RNAm como alvo. Assim, expressões desreguladas de miRNA podem alterar respostas celulares particulares direcionando 
ou contribuindo para o desenvolvimento de doenças. Tanto na asma como na DPOC, miRNAs regulam a resposta imune. Eles não apenas participam da determinação do fenótipo da célula dendrítica e da diferenciação linfocitária, como atuam na regulação da inflamação da via aérea e do remodelamento brônquico. ${ }^{94}$ Por exemplo, numa avaliação dos miRNAs com expressões diferenciadas na asma, os miRNA-34/449, let7, miRNA-19, miRNA-21 e miRNA-455 foram identificados em vários tipos celulares em pulmóes de asmáticos, havendo indícios de que estejam envolvidos na diferenciação epitelial, na produção de muco, no remodelamento da via aérea e na inflamação brônquica. Entretanto, ainda não foi possível identificar quais genes são alvos de cada miRNA específico. ${ }^{95}$ Diversos estudos em andamento buscam descobrir como os miRNA funcionam individualmente na regulação das respostas imunes aos diferentes fatores ambientais e infecciosos no terreno pulmonar. $^{96}$

Certamente, o emaranhado de processos patogênicos conjugando mecanismos múltiplos é o responsável pela asma ter um grande espectro de apresentaçôes clínicas. Tanto a asma quanto a DPOC apresentam diferenças fenotípicas claras entre os sexos. $\mathrm{Na}$ infância, a asma é mais prevalente entre meninos; na idade adulta, a prevalência é maior entre as mulheres. Há outras diferenças evidentes entre as prevalências dos fenótipos da asma entre os sexos. As formas graves e a asma de início tardio são mais frequentes no sexo masculino. Ainda está por esclarecer se isso se deve à participação dos hormônios sexuais na concentração de citocinas inflamatórios ou nas diferenças nas funções das células dendríticas e macrófagos. $^{97}$ Existe a asma que se inicia na infância e a asma que se inicia na idade adulta. A primeira é usualmente associada com história familiar de doença alérgica, sensibilização alergênica, infecções virais na primeira infância e mais prevalente no sexo masculino. A segunda está mais associada com tabagismo, obesidade e exposiçôes ocupacional. ${ }^{98}$ As arquiteturas genéticas de ambas são diferentes. ${ }^{99}$ Existe a asma Th2 alto e a Th2 baixo, existe a asma neutrofílica, e assim por diante. Possivelmente, diferentes arranjos envolvendo momento da exposição, fatores genéticos, microbioma, agentes externos, estresse emocional e outros fatores participam da gênese das variaçóes da asma. Embora a disseminação do tabagismo entre as mulheres venha aproximando as taxas de prevalência da DPOC entre os sexos, certamente há diferenças entre eles no que se refere à DPOC. Por uma provável razão genética, a DPOC causada pelo fumo é mais grave entre as mulheres. Possivelmente, fatores hormonais também estão envolvidos, diferenciando o metabolismo da fumaça do tabaco e o desenvolvimento/senescência pulmonar. $^{100}$ 
Em 1908, ao descobrir os fagócitos, Ilya Ilyich Mechnikov dividiu um Prêmio Nobel com Paul Ehrlich (anticorpos neutralizantes), colocando o estudo da imunologia no lugar de destaque que ocupa até hoje. ${ }^{101}$ Atualmente, sabe-se que um fagócito, o macrófago, tem papel de destaque na patogênese da asma e da DPOC. Sua diversidade e plasticidade na imunidade inata e adquirida, modulada por miRNAs, coloca essa célula como personagem importante no palco da inflamação pulmonar. O miRNA-155 é responsável pelos efeitos pró-inflamatórios dos macrófagos. ${ }^{102}$ Baseado no fenótipo, os macrófagos são classificados em "classicamente ativados" (M1) e "alternativamente ativados" (M2). Esses últimos, com base no perfil de expressão genética, são subcategorizados em M2a, M2b, M2c e M2d. A metamorfose fenotípica do macrófago é o fator regulador na iniciação, progressão e término de diversas doenças inflamatórias, asma ${ }^{103}$ e DPOC inclusive. $\mathrm{O}$ fenótipo $\mathrm{M} 2$, envolvido no reparo tecidual e recuperação da homeostasia no microambiente pulmonar, tem papel importante na asma. Já o fenótipo M1 está envolvido na progressão da asma. ${ }^{104} \mathrm{~A}$ inflamação crônica da via aérea observada na DPOC é um processo direcionado pela NF$\kappa \beta$ que leva à ativação al ternada de macrófagos alveolares, resultando na geração de TGF $\beta$, IL-10 e ácido retinóico dependentemente da produção de Tregs e Foxp3. ${ }^{105}$ Além disso, macrófagos alveolares promovem a expressão amplificada de TGF $\beta$ e IL-10, induzindo um ambiente imunossupressivo no pulmão. ${ }^{104}$

Ações no eixo intestino-pulmão e a composição/desequilíbrio da MP estão associadas a diversas doenças respiratórias crônicas, como fibrose cística, bronquiectasias, asma e DPOC, por exemplo. ${ }^{106}$ Os microrganismos presentes na MP produzem estímulos epigenéticos, ligantes estruturais e metabólitos que interagem com o hospedeiro dando origem a efeitos funcionais sobre a imunidade inata e adaptativa que influenciam a gênese e a progressáo das doenças citadas. Não há dúvidas de que disbioses na MI e MP geram desequilíbrio entre as populações simbióticas e patogênicas e consequentes alteraçóes imunes e respostas inflamatórias inadequadas, aspectos da asma ${ }^{107}$ e da DPOC. ${ }^{108,109}$ Entretanto, ainda não se sabe se essas disbioses são causa ou efeito daquelas doenças. ${ }^{109,110}$ Em pessoas saudáveis, a MP, que inclui o bacterioma, o viroma e o micobioma, contém seis famílias bacterianas dominantes: Firmicutes (incluindo Streptococcus e Vellonella), Bacteroides (incluindo Prevotella, Proteobacteria, Fusobacteria, Acidobacteria e Actinobacteria. O viroma pulmonar contém a família Anelloviridae e vários bacteriófagos. $\mathrm{O}$ micobioma é composto principalmente por Eremothecium, Systenostrema e Malassazia Em asmáticos e portadores de DPOC, os microrganismos predominantes são outros, havendo variação na composição de acordo com o fenótipo e 
a situação do momento. ${ }^{110,111}$ Uma infecção ou uma doença pulmonar pode romper o equilíbrio entre as populaçóes simbióticas e patobiônticas do MP e quebrar o equilíbrio entre T-helpers e T-regulatórios. Tanto na asma como na DPOC, fatores como gravidade da doença, grau da inflamação, exacerbação e tipo de tratamento afetam a composição da MP. A presença de proporções de bactérias específicas nas vias aéreas pode influenciar a resposta imune do hospedeiro e interferir com o fenótipo da doença. ${ }^{112}$

Modificações epigenéticas são fatores comprovadamente associados à inserção e à progressão de doenças crônicas pulmonares, como a asma e a DPOC.A epigenética constitui uma ponte transpondo o hiato mecanístico entre os fatores de risco ambientais e genéticos, promovendo uma memória duradoura das exposiçôes prejudiciais iniciais na asma e na DPOC. ${ }^{113}$ A metilação do DNA, mecanismo epigenético clássico mais frequentemente associado às duas doenças, pode ser herdada através de várias gerações (efeito transgeracional). ${ }^{114} \mathrm{~A}$ investigação dos processos moleculares envolvidos, através de algoritmos de redes poderá elucidar as ligaçôes mecanísticas entre exposições (genéticas e epigenéticas) variáveis e a patogênese das doença pulmonares, apontando para estratégias de prevenção primária e possibilitando a tão almejada medicina de precisão.

Certamente, as dificuldades e obstácu- los gerados no cotidiano dos portadores de asma e de DPOC geram impactos na qualidade de vida tanto no plano físico como no mental. Ansiedade e depressão são duas disfunçóes neurocognitivas e emocionais marcantes nos pacientes e proporcionais à gravidade dos sintomas. Entretanto, o estresse psicológico também está incluído entre os fatores causais de ambas as doenças. Merece ressalva que já no século XII, o aspecto emocional da asma foi citado e, recentemente, surgiram evidências de que distúrbios emocionais geram asma. $\mathrm{Na}$ década de 30, os trabalhos de Alexander e colaboradores, do Instituto de Psicanálise de Chicago, influenciaram fortemente a teoria de que o componente psicossomático da asma era importante na patogenia da doença. ${ }^{115}$ Publicações científicas nas últimas duas décadas confirmam que estresse psicológico no período pré-natal ou no início da vida (ansiedade ou depressão materna, por exemplo) eleva o risco de doenças respiratórias na infância. Revisóes sistemáticas e metanálises indicam sua importância no desenvolvimento de sibilos, asma e outras doenças atópicas (eczema e rinite alérgica), com muitos estudos evidenciando a relação exposiçãoefeito. ${ }^{116} \mathrm{O}$ impacto do estresse na asma também pode ser diferente dependendo do momento da exposição. Recém-natos de ambos os sexos são susceptíveis ao estresse perinatal, mas o efeito é diferente. A exposição ao estresse pré-natal pode amplificar 
a importância de outros fatores (exposição pré-natal à poluição aérea gerada pelo trânsito, p. ex.) na determinação do risco de doença respiratória na infância. $\mathrm{O}$ estresse psicológico no início da vida também foi associado à gênese da DPOC. ${ }^{117}$

$\mathrm{O}$ estresse crônico também interfere com a progressão da asma e da DPOC, já que leva a mudanças biológicas, como a expressão de genes imunológicos, mudanças na expressão genética dos receptores betaadrenérgicos e de corticosteroides, na regulação de citocinas e no eixo hipófisehipotálamo, alterando os níveis de cortisol. ${ }^{117}$ Interaçôes complexas entre intensidade da exposição ao estresse, momento, sexo e concomitância da exposição a fatores ambientais definem subgrupos susceptíveis. De algum modo, há associaçóes interativas do estresse com mecanismos básicos para a patogenia da asma e para o desenvolvimento pulmonar, gerando uma sequência de eventos que, por mecanismos neuroimunológicos ainda não esclarecidos ${ }^{118}$, interferem com as funções imune, neuroendócrinica e autonômica, e com o estresse oxidativo. ${ }^{119}$ A elucidação dos mecanismos envolvidos nas interaçôes entre o estresse psicológico e as mudanças fisiológicas pulmonares por ele induzidas durante períodos vulneráveis da vida que contribuem para o risco maior de doenças respiratórias poderá levar ao desenvolvimento de estratégias preventivas e, talvez, a intervençóes terapêuticas.

\section{Conclusão}

A asma e a DPOC compartilham fatores causais comuns desde a fase fetal. A ponte molecular entre as bases genéticas e os fatores de risco ambientais que resulta nos mecanismos patogênicos de ambas as doenças é representada pelos mecanismos epigenéticos que incluem metilação do DNA, modificações de histonas, eventos pós-translacionais e miRNAs. Genética e epigenética intermediando os efeitos dos elementos externos, tais como alérgenos, gases e vapores tóxicos, fármacos, fatores ambientais, hábitos do cotidiano e emoçóes, e em conjunto com a influência bidirecional dos genomas humano e microbiômico, que traduz aqueles fatores em processos patogênicos no aparelho respiratório são os principais tijolos na construção de ambas. Variaçóes entre os tijolos talvez sejam determinantes para as diferenças anatomopatológicas, funcionais ou sensibilidade terapêutica entre as duas. Os detalhes envolvidos na interação entre todos os fatores envolvidos que resulta no desenvolvimento e progressão da asma e da DPOC ainda não foram esclarecidos. Todos aguardamos que a utilização de plataformas ômicas permita a análise detalhada dos dados epigenômicos e microbiômicos e esclareça os mecanismos envolvidos na transição 
estratificada de um estado de "pré-doença" para o de doença apontando para estratégias de prevenção primária com instrumentos capazes de desconstruir aquelas doenças.

\section{REFERÊNCIAS BIBLIOGRÁfICAS}

1. Maria José Rosa MJ, Lee A, Wright RJ. Evidence establishing a link between prenatal and early life stress and asthma development. Curr Opin Allergy Clin Immunol 2018 Apr;18(2):148-158.

2. Ciba Guest Symposium. Terminology, definitions and classifications of chronic pulmonary emphysema and related conditions. Thorax 1959;14: 286-99.

3. Hogg JC, Macklem PT, Thurlbeck WM. Site and nature of airway obstruction in chronic obstructive lung disease. N Engl J Med 1968 Jun 20;278(25):1355-60.

4. Hogg JC, Chu F, Utokaparch S et cols. The nature of small-airway obstruction in chronic obstructive pulmonary disease. N Engl J Med 2004 Jun 24;350(26):2645-53.

5. Global initiative for chronic obstructive lung disease. Global Strategy for the diagnosis, management, and prevention of chronic obstructive pulmonar disease. 2021 Report.
6. Wan ES, Qiu W, Baccarelli A, et al. Cigarette smoking behaviors and time since quitting are associated with differential DNA methylation across the human genome. Hum Mol Genet 2012; 21: 3073-3080

7. Singh D, Agusti A, Anzueto A, et al. Global strategy for the diagnosis, management, and prevention of chronic obstructive lung disease: the GOLD science committee report 2019. Eur Respir J 2019; 53: 1900164.

8. Helmont, Jean Baptiste van, 15771644. Collection: Early English Books Online

9. Vandenplas O, Malo J-L. Definitions and types of work-related Asthma: a nosological approach. Eur Respir J 2003;21:706-12.

10. Salter HH. Asthma: its pathology and treatment, 2nd ed. London: Churchill; 1868.

11. Osler W. Diseases of the respiratory system: bronchial asthma. In: The principles and practice of medicine, 4th ed. New York: D. Appleton and Company; 1901. p. 628-632.

12. Blackey $\mathrm{CH}$. Experimental researches on the causes and nature of catarrhus aestivus (hay fever or hay-asthma). London: Ballie' re, Tindall and Cox; 1873.

13. Rackemann FM. Intrinsic Asthma. J 
Allergy 1940;11(2):147-62.

14. Meltzer SJ. Bronchial asthma as a phenomenon of anaphylaxis. JAMA 1910; 55:1021-1024.

15. Krempski JW, Dant CD, Nadeau KC. The origins of allergy from a system approach. Ann Allergy Asthma Immunol 2020;125(5):507-16.

16. Fowler JK, Godlee RJ. Asthma. In: The diseases of the lungs. New York: Longmans, Green, and Company; 1898. p. 183-194.

17. Global Initiative for Asthma. Global Strategy for Asthma management and prevention. Update 2021.

18. Gibson PG, Simpson JL The overlap syndrome of asthma and COPD: what are its features and how important is it? Thorax 2009 Aug;64(8):728-35.

19. Boulet, L.P.; Sterk, P.J. Airway remodelling: The future. Eur. Respir. J. 2007, 30, 831-834.

20. Barnes PJ. Cellular and molecular mechanisms of asthma and COPD. Clin Sci (Lond) 2017 Jul 1;131(13):1541-1558.

21. Mootz M, Jakwerth CA, SchimidtWeber CB et col. Secretoglobins in the big Picture of immuneregulation in airway diseses. Allergy 2021;00:1-11.

22. Kuruvilla ME, Lee FE, Lee GB.Understanding Asthma Phenotypes, Endotypes, and Mechanisms of Disease. Clin
Rev Allergy Immunol. 2019 Apr;56(2):219-233.

23. El-Husseini ZW, Gosens R, Dekker $\mathrm{F}$ et col. The genetics of asthma and the promise of genomics-guided drug target Discovery. Lancet Respir Med 2020;8(10):1045-56.

24. Van Eerdewegh P, Little RD, Dupuis $\mathrm{J}$ et cols. Association of the ADAM33 gene with asthma and bronchial hyperresponsiveness. Nature. 2002;418(6896):426-30

25. Balaci L, Spada MC, Olla N et cols. IRAK-M is involved in the pathogenesis of early-onset persistent asthma. Am J Hum Genet. 2007;80(6):1103-14.

26. Koppelman GH, Meyers DA, Howard TD et cols. Identification of PCDH1 as a novel susceptibility gene for bronchial hyperresponsiveness. Am J Respir Crit Care Med. 2009;180(10):929-35.

27. Moffatt MF, Kabesch M, Liang L, et al. Genetic variants regulating ORMDL3 expression contribute to the risk of childhood asthma. Nature 2007; 448: 470-73.

28. Silverman EK. Genetics of COPD. Annu Rev Physiol. 2020 Feb 10;82:413-431.

29. Shrine N, Guyatt AL, Erzurumluoglu AM et cols. New genetic signals for lung function highlight pathways and 
chronic obstructive pulmonary disease associations across multiple ancestries. Nat Genet. 2019 Mar;51(3):481-93.

30. Beadle GW, Tatum EL. Genetic control of biochemical reactions in Neurospora. Proc Natl Acad Sci USA. 1941;27:499-506.

31. Vidal M, Cusick ME, Barabási A-L. Interactome networks and human diseases. Cell 2011;144(6):986-98.

32. Wiklund P, Karhunen V, Richmond RC, et al. DNA methylation links prenatal smoking exposure to later life health outcomes in offspring. Clin Epigenetics 2019; 11: 97.

33. Bonetta L. Interactome under construction. Nature 2010;468:851-2

34. Qi C, Xu C-J, Koppelman GH. The role of epigenetics in the development of childhood Asthma. Expert Rev Clin Immunol 2019 Dec;15(12):12871302.

35. Potaczek, D.P.; Harb, H.; Michel, S.; Alhamwe, B.A.; Renz, H.; Tost, J. Epigenetics and allergy: From basic mechanisms to clinical applications. Epigenomics 2017, 9, 539-571.

36. Muhammad T Salam. Asthma epigenetics. Adv Exp Med Biol 2014;795:183-99.

37. Vidigal, J.A.; Ventura, A. The biological functions of miRNAs: Lessons from in vivo studies. Trends Cell Biol. 2015, 25, 137-147.
38. Wanet A, Tacheny A, Arnould T, Renard P. miR-212/132 expression and functions: within and beyond the neuronal compartment. Nucleic Acids Res. 2012;40(11):4742-53.

39. Moheimani F, Hsu AC-Y, Reid AT et cols. The genetic and epigenética landscapes of the epithelium in Asthma. Respir Res 2016;17:119-34.

40. Benincasa G, DeMeo DL, Glass K et cols. Epigenetics and pulmonar diseases in the horizon of precision medicine: a review. Eur Respir J 2021;57:2003406.

41. DeVries A, Vercelli D. Epigenetic mechanisms in asthma. Ann Am Thorac Soc 2016; 131: S48-S50

42. Accordini S, Calciano L, Johannessen A, et al. A three-generation study on the association of tobacco smoking with asthma. Int J Epidemiol 2018; 47: 1106-1117.

43. Giuditta Benincasa G, Dawn L DeMeo DL, Kimberly Glass K et cols. Epigenetics and pulmonary diseases in the horizon of precision medicine: a review. Eur Respir J 2021 Jun 10;57(6):2003406.

44. Milligan KL, Matsui E, Sharma H. Asthma in Urban Children: Epidemiology, Environmental Risk Factors, and the Public Health Domain. Curr Allergy Asthma Rep 2016 Apr;16(4):33. 
45. Stillwell W. An Introduction to Biological Membranes: Composition, Structure and Function. Second edition. 2016.

46. Joshi, BS, de Beer MA, Giepmans BNG et col. Endocytosis of Extracellular Vesicles and Release of Their Cargo from Endosomes. ACS Nano 2020, 14, 4444-55.

47. Lee J-U, Kim JD, Park C-S. GeneEnvironment Interactions in Asthma: Genetic and Epigenetic Effects. Yonsei Med J 2015 Jul;56(4):877-86.

48. Marks GB. Environmental factors and gene-environment interactions in the aetiology of Asthma. Clin Exp Pharmacol Physiol 2006 Mar;33(3):285-9.

49. Soriano, J.B.; Abajobir, A.A.; Abate, K.H et al. A Global, regional, and national deaths, prevalence, disabilityadjusted life years, and years lived with disability for chronic obstructive pulmonary disease and asthma, 1990-2015: A systematic analysis for the Global Burden of Disease Study. Lancet Respirat. Med. 2017, 5, 691706.

50. Serebrisky, D.; Wiznia, A. Pediatric Asthma: A Global Epidemic. Ann. Glob. Health 2019, 85.

51. Ruvuna L, Sood A. Epidemiology of Chronic Obstructive Pulmonary Disease. Clin Chest Med 2020
Sep;41(3):315-327.

52. Gilkes A, Ashworth M, Schofield $P$ et cols. Does COPD risk vary by ethnicity? A retrospective crosssectional study. Int J Chron Obstruct Pulmon Dis 2016 Apr 7;11:739-46.

53. Drake KA, Galnter JM, Burchard EG. Race, Ethnicity and Social Class and the Complex Etiologies of Asthma . Pharmacogenomics. 2008 April ; 9(4): 453-462.

54. Bhan N, Kawachi I, Glymour MM et col. Time trends in racial and ethnic disparities in asthma prevalence in the United States from the Behavioral Risk Factor Surveillance System (BRFSS) Study (1999-2011). Am J Public Health 2015;105(06): 1269-1275.

55. Lara M, Akinbami L, Flores G et col. Heterogeneity of childhood asthma among Hispanic children: Puerto Rican children bear a disproportionate burden. Pediatrics 2006;117(01):4353

56. Gorman BK, Chu M. Racial and ethnic differences in adult asthma prevalence, problems, and medical care. Ethn Health 2009;14 (05):527552

57. Davis AM, Kreutzer R, Lipsett $\mathrm{M}$ ett cols. Asthma prevalence in Hispanic and Asian American ethnic subgroups: results from the California Healthy Kids Survey. Pediatrics 2006; 
118(02):e363-e370 21 Brim SN, Rudd RA, F

58. Bianconi E, Piovesan A, Facchin F et als. An estimation of the number of cells in the human body. Annals Hum Biol 2013,40(6):463-71.

59. Ursell LK, Metcalf JL, Parfrey LW, Knight R. Defining the human microbiome. Nutr Rev 2012;70(1):S38-S44.

60. Levy M, Aleksandra A. Kolodziejczyk AA, Christoph A. Thaiss CA et col. Dysbiosis and the immune system. Nature Reviews Immunology 2017;17:219-32.

61. Nagpal R, Tsuji H, Takahashi T, et al. Sensitive quantitative analysis of the meconium bacterial microbiota in healthy term infants born vaginally or by cesarean section. Front Microbiol 2016;7:1997

62. Human Microbiome Project Consortium. Structure, function and diversity of the healthy microbiome. Nature 2012;486:207-14.

63. Dominguez-Bello MG, GodoyVitorino F, Knight R et al. Role of microbiome in human development. Gut 2019;68:1108-14.

64. Gensollen T, Iyer SS, Kasper DL, Blumberg RS. How colonization by microbiota in early life shapes the immune system. Science 2016;352:539-544
65. Nicodemus-Johnson J, Laxman B, Stern RK et cols. Maternal asthma and microRNA regulation of soluble HLA-G in the airway. J Allergy Clin Immunol. 2013;131(6):1496-503.

66. Demenais F, Margaritte-Jeannin P, Australian Asthma Genetics Consortium (AAGC) collaborators, et al. Multiancestry association study identifies new asthma risk loci that colocalize with immune-cell enhancer marks. Nat Genet. 2018;50:42-53.

67. Manolio TA, Collins FS, Cox NJ et cols. Finding the missing heritability of complex diseases. Nature 2009;461:747-53.

68. Long A, Bunning B, Sampath V et cols. Epigenetics and the Environment in Airway Disease: Asthma and Allergic Rhinitis. Adv Exp Med Biol 2020;1253:153-181.

69. Jose L Gomez JL. Epigenetics in Asthma. Curr Allergy Asthma Rep 2019 Nov 27;19(12):56.

70. Ragland MF, Benway CJ, Lutz SM et cols. Genetic advances in chronic obstructive pulmonar disease. Insights from COPDGene. Am J Respir Crit Care Med 2019;200(6):677-90.

71. Sakormsakolpat P, Prokopenko D, Lamontagne $\mathrm{M}$ et cols. International DPOC Genetics Consortium. Nat Genet 2019;51(3):494-505.

72. Sadeghnejad A, Ohar JA, Zheng 
SL et al. Adam33 polymorphisms are associated with COPD and lung function in long-term tobacco smokers. Respir Res 2009;10:21.

73. Li X, Howard TD, Zheng SL et al. Genome-wide association study of asthma identifies RAD50-IL13 and HLA-DR/DQ regions. J Allergy Clin Immunol 2010;125 (2):328-335.

74. Sadeghnejad A, Meyers DA, Bottai M et cols. IL13 promoter polymorphism $-1112 \mathrm{C} / \mathrm{T}$ modulates the adverse effect of tobacco smoking on lung function. Am J Respir Crit Care Med 2007;176:748-752.

75. He JQ, Foreman MG, Shumansky $\mathrm{K}$ et cols. Associations of IL6 polymorphisms with lung function decline and COPD. Thorax 2009;64:698-704.

76. DeMeo DL, Campbell EJ, Barker AFet cols. IL10 polymophisms are ssociated with airflow obstruction in severe $\alpha 1$ antitrypsin deficiency. 2008;38:114120.

77. Hunninghake GM, Cho MH, Tesfaigzi Y, et cols. MMP12, lung function, and COPD in highrisk populations. N Engl J Med 2009;361(27):2599-2608.

78. Wu L, Chau J, Young RP, Polorny V, Mills GD, Hopkins R, et al. Transforming growth factor-beta 1 genotype and susceptibility to chronic obstructive pulmonary disease. Thorax 2004;59(2):126-129.

79. Spira A, Beane JE, Shah Vet cols. Airway epithelial gene expression in the diagnostic evaluation of smokers with suspect lung cancer. Nat Med. 2007 Mar; 13(3):361-6.

80. Rennard SL, Vestbo J. COPD: the dangerous underestimate of $15 \%$. Lancet 2006;367:1216-9.

81. Brusselle GG, Joos GF, Bracke KR. New insights into the immunology of chronic obstructive pulmonary disease. Lancet 2011; 378: 1015-1026.

82. Garudadri S, Woodruff PG. Targeting chronic obstructive pulmonary disease phenotypes, endotypes, and biomarkers. Ann Am Thorac Soc 2018; 15: S234-S238

83. Christenson SA, Steiling K, van den Berge M, et al Asthma-COPD overlap. Clinical relevance of genomic signatures of type 2 inflammation in chronic obstructive pulmonary disease. Am J Respir Crit Care Med 2015; 191: 758-766.

84. DeVries A, Donata Vercelli D. Epigenetic Mechanisms in Asthma. Ann Am Thorac So 2016 Mar; 13 Suppl 1(Suppl 1):S48-50.

85. M. Kumar, W. Seeger, R. Voswinckel. Senescence-associated secretory phenotype and its possible role in chronic obstructive pulmonary 
disease. Am J. Respir Cell Mol Biol 2014;51:323-33.

86. M. Abbas, L. Jesel, C. Auger, Let cols. Endothelial microparticles from acute coronary syndrome patients induce premature coronary artery endothelial cell aging and thrombogenicity: role of the Ang II/AT1 receptor/NADPH oxidase-mediated activation of MAPKs and PI3-kinase pathways. Circulation 2017;135:280-96,

87. Fujita Y, Kosaka N, Araya J et cols. Extracellular vesicles in lung microenvironment and pathogenesis. Trends Mol Med 2015;21:533-42,

88. Kadota T, Fujita Y, Yoshioka Y et als. Emerging role of extracellular vesicles as a senescence-associated secretory phenotype: Insights into the pathophysiology of lung diseases. Mol Aspects Med. 2018 Apr;60:92-103.

89. Thomashow MA, Shimbo D, Parikh MA et cols. Endothelial microparticles in mild chronic obstructive pulmonary disease and emphysema. The multiethnic study of atherosclerosis chronic obstructive pulmonary disease study Am J Respir Crit Care Med 2013;188:60-68.

90. Lacedonia D, Carpagnano GE, Trotta $T$ et cols. Microparticles in sputum of COPD patients: a potential biomarker of the disease? COPD 2016;11:52733 ,
91. Sangaphunchai P, Todd I, Fairclough LC. Extracellular vesicles and asthma: A review of the literature. Clin Exp Allergy 2020 Mar;50(3):291-307.

92. Alhamwe BA, Potaczek DP, Miethe S. Extracellular Vesicles and AsthmaMore Than Just a Co-Existence. Int J Mol Sci 2021 May 7;22(9):4984.

93. Szymczak I, Wieczfinska J, Pawliczak R. Molecular background of miRNA role in Asthma and COPD: na updated insight. Biomed Res Int 2016;2016:7802521.

94. Kai W, Qian XU, Zu Qun WU. MicroRNAs and Asthma regulation. Iran J Allergy Asthma Immunol 2015;14(2):120-5.

95. van den Berge M, Tasena H. Role of microRNAs and exosomes in Asthma. Curr Opin Pulm Med. 2019 Jan;25(1):87-93.

96. Weidner J, Bartel S, Kılıç A et cols. Spotlight on microRNAs in allergy and Asthma. Allergy 2021 Jun;76(6):1661-1678.

97. Fuseini H, Newcomb DC. Mechanisms Driving Gender Differences in Asthma. Curr Allergy Asthma Rep 2017 Mar;17(3):19.

98. de Nijs SB, Venekamp LN, Bel $\mathrm{EH}$. Adult-onset asthma: is it really different? Eur Respir Rev 2013;22:4452

99. Ferreira MAR, Mathur R, Vonk 
$\mathrm{JM}$, et al. Genetic architectures of childhood- and adult-onset asthma are partly distinct. Am J Hum Genet 2019;104:665-684

100. Nicolini A, Elena Barbagelata E, Elena Tagliabue E et cols. Gender differences in chronic obstructive pulmonary diseases: a narrative review. Panminerva Med 2018 Dec;60(4):192-199.

101. Kaufmann SHE. Immunology's coming of age. Front Immunol 2019;Apr 3,10:684

102. Yuan Z et al. TREM-1-accentuated lung injury via miR-155 is inhibited by LP17 nanomedicine, Am J Physiol Lung Cell Mol Physiol 2016;310(5):L426-38.

103. Moreira AP, Hogaboam CM. Macrophages in allergic Asthma: fine-tuning their pro- anda tiinflammmatory actions for disease resolution. J Interferon Cytokine Res 2011;31(6):485-91.

104. Arora S, Dev K, Agarwal B et cols. Macrophages: Their role, activation and polarization in pulmonary diseases. .Immunobiology. 2018 AprMay;223(4-5):383-396.

105. Zaynagetdinov $\mathrm{R}$ et al. Chronic NFkappaB activation links COPD and lung câncer through Generation of na immunosuppressive microenvironment in the lungs. Oncotarget
2016;7(5):5470-82.

106. Budden KF, Shukla DS, Rehman

SF et cols. The microbiome is respiratory disease 2 . Functional effects of the microbiota in chronic respiratory disease. Lancet Respir Med 2019;7:907-20.

110. Hufnagl K, Pali-Schöll I, Roth-Walter F, Jensen-Jarolim E. Dysbiosis of the gut and lung microbiome has a role in asthma. Semin Immunopathol. 2020 Feb;42(1):75-93.

111. Karin Hufnagl K, Pali-Schöll I, RothWalter $\mathrm{F}$ et col. Dysbiosis of the gut and lung microbiome has a role in Asthma. Semin Immunopathol 2020 Feb;42(1):75-93.

112. Mammen MJ, Sethi S. COPD and the microbiome. Respirology 2016 May;21(4):590-9.

113. Barcik W, T Boutin RCT, Milena Sokolowska M et al. The Role of Lung and Gut Microbiota in the Pathology of Asthma. Immunity $2020 \mathrm{Feb}$ 18;52(2):241-255.

113. Mammen MJ, Sethi S. COPD and the microbiome. Respirology 2016 May;21(4):590-9.

114. Dima E, Kyriakoudi A, Kaponi M et cols. The lung microbiome dynamics between stability and exacerbation in chronic obstructive pulmonary disease (COPD): Current perspectives. Respir Med 2019 Oct;157:1-6. 
115. den Dekker HT, Burrows K, Felix JF, et al. Newborn DNA-methylation, childhood lung function, and the risks of asthma and COPD across the life course. Eur Respir J 2019; 53: 1801795.

116. Wu CC, Hsu TY, Chang JC, et al. Paternal tobacco smoke correlated to offspring asthma and prenatal epigenetic programming. Front Genet 2019; 10: 471.

117. Alexander F, French TM, Pollock GH. Psychosomatic specifcity, Vol 1: experimental study and results. Chicago: University of Chicago Press, 1968.

118. Kim F.E. van de Loo, Marleen M.H.J. et cols. Prenatal maternal psychological stress and childhood asthma and wheezing: a meta-analysis. European Respiratory Journal 2016 47: 133-146;

119. Barnthouse M, Jones BL. The Impact of Environmental Chronic and Toxic Stress on Asthma. Clinical Reviews in Allergy \& Immunology 2019;57:42738.

120. Ader R, Cohen N, Felten D. Psychoneuroimmunology: interactions between the nervous system and the immune system. Lancet 1995;345:99103,

121. Wright RJ, Rodriguez M, Cohen S. Review of psychosocial stress and asthma: an integrated biopsychosocial approach. Thorax. 1998; 53:10661074. 